\title{
The Levels of Cortisol and Oxidative Stress and DNA Damage in Child and Adolescent Victims of Sexual Abuse with or without Post-Traumatic Stress Disorder
}

\author{
Şeref Şimşek ${ }^{1}$, Tuğba Yüksel ${ }^{1}$, İbrahim Kaplan², Cem Uysal ${ }^{3}$, and Hüseyin Aktaş ${ }^{1}$ \\ ${ }^{1}$ Department of Child Psychiatry, Dicle University, Medical School, Diyarbakır, Turkey \\ 2Department of Biochemistry, Dicle University, Medical School, Diyarbakır, Turkey \\ ${ }^{3}$ Department of Forensic Medicine, Dicle University, Medical School, Diyarbakır, Turkey
}

Objective The aim of this study was to investigate whether cortisol and oxidative stress levels and DNA damage differ between individuals who developed PTSD or not following a sexual trauma.

Methods The study included 61 children aged between 5 and 17 years who sustained sexual abuse (M/F: 18/43). The patients were divided into two groups: patients with PTSD and patients without PTSD based, based on the results of a structured psychiatric interview (K-SADS-PL and CAPS-CA). Cortisol, glutathione peroxidase (GPx), superoxide dismutase (SOD), coenzyme Q, 8-Hydroxy-2-Deoxyguanosine (8-OHdG) were all evaluated by the ELISA method.

Results Our evaluation revealed a diagnosis of PTSD in $51 \%(n=31)$ of victims. There was no significant difference between the groups with or without PTSD in terms of cortisol, GPx, SOD, coenzyme Q, and 8-OHdG levels. There was no correlation between CAPS scores and GPx, SOD, coenzyme Q, and 8-OHdG levels between patients with or without PTSD. In patients with PTSD, both cortisol and 8-OHdG levels decreased with increasing time after trauma, and there was no significant correlation with cortisol and 8-OHdG levels in patients without PTSD.

Conclusion Although the present study did not find any difference between the groups in terms of 8-OHdG concentrations, the decreases in both cortisol and 8-OHdG levels with increasing time after trauma is considered to indicate a relationship between cortisol and DNA damage.

Psychiatry Investig 2016;13(6):616-621

Key Words Cortisol, DNA damage, Oxidative stress, PTSD, Sexual abuse, Trauma.

\section{INTRODUCTION}

Trauma is defined as a direct exposure of an individual to a severely distressing event such as experiencing or witnessing a real death or death threat, severe injury or any threat to the physical integrity of an individual. ${ }^{1}$ Sexual abuse is one of the most severe forms of trauma, considering its future consequences. Brain tissue continues its development in child-

Received: April 26, 2015 Revised: June 23, 2015

Accepted: July 2, 2015 Available online: November 21, 2016

$\bowtie$ Correspondence: Şeref Şimşek, MD

Dicle University, Medical School, Department of Child Psychiatry, Sur, Diyarbakur, 21280, Turkey

Tel: +90-412-248-80-01/5828, Fax: +90-412-248-84-40

E-mail: drserefsimsek@gmail.com

(a) This is an Open Access article distributed under the terms of the Creative Commons Attribution Non-Commercial License (http://creativecommons.org/licenses/by$\mathrm{nc} / 3.0$ ) which permits unrestricted non-commercial use, distribution, and reproduction in any medium, provided the original work is properly cited. hood and during adolescence. ${ }^{2}$ Traumas experienced during these periods have been reported to have more serious consequences. ${ }^{3}$

The individuals who have experienced trauma often exhibit one or more psychiatric disorders, including post-traumatic stress disorder (PTSD), depression, dissociative disorder, alcohol and substance abuse, personality disorders, and suicide attempts. ${ }^{4}$ Although PTSD is the most commonly encountered psychiatric condition after trauma, not all patients who experience trauma develop PTSD. Some individual and environmental risk factors are associated with the development of PTSD. The type and severity of trauma are the most important predictors of PTSD. ${ }^{5}$

Oxidative stress implies overproduction of reactive oxygen species (ROS) and/or failure of antioxidant defense mechanisms. ${ }^{6}$ Brain tissue is vulnerable to oxidative stress due to its higher demand for oxygen. ${ }^{7-9}$ Oxidative stress also impairs 
normal brain functions through the inhibition of neurogenesis, altering neuronal transmission, and inducing mitochondrial dysfunction. ${ }^{10}$

The anti-oxidant defense system involves enzymatic and non-enzymatic components. Superoxide dismutase (SOD) and glutathione peroxidase (GPx) are anti-oxidant enzymes. ${ }^{11}$ Coenzyme $\mathrm{Q}$ is a non-enzymatic anti-oxidant. ${ }^{12}$ Coenzyme $\mathrm{Q}$ is a lipid-soluble vitamin-like substance, and it is an important cofactor in mitochondrial electron transport from complex I to complex III. ${ }^{13}$ It is found at high concentrations in the brain and heart. ${ }^{14} 8$-Hydroxy-2-Deoxyguanosine (8OHdG) is a biochemical marker of ROS-mediated DNA damage. ${ }^{15}$

The human and animals studies demonstrated that oxidative stress is related to anxiety. ${ }^{16-21}$ In animal model of PTSD, inflammation and oxidative stress were reported to play a critical role in the development and exacerbation of PTSD. ${ }^{22}$ There are also studies that did not report a significant difference between patients with PTSD and the control group in terms of oxidative stress. ${ }^{23,24}$

It was reported that oxidative stress could be a critical molecular linkage between the hypothalamic-pituitary-adrenal (HPA) axis dysfunction and mental disorders. ${ }^{25}$ It was also reported that the stress-induced increase in cortisol levels accelerates glucose metabolism and production of reactive oxygen species. ${ }^{26}$

The present study considered the fact that children and adolescents are more susceptible to the effects of trauma, and there are no studies demonstrating the relationship between oxidative stress and PTSD in this particular age group; the studies on adults have reported controversial data. The aim of this study was to investigate whether cortisol and oxidative stress levels and DNA damage differ between individuals who developed PTSD or not following a sexual trauma.

\section{METHODS}

\section{Study sample}

The study was conducted in the Department of Child Psychiatry at Dicle University Training and Research Hospital. The study data were collected between July 2013 and February 2014.

A total of 61 children, aged between 5 and 17 years (18 males and 43 females), participated in the study. CSA included intercourse, attempted intercourse, oral-genital contact, fondling of genitals directly or through clothing, exhibitionism or exposing children to adult sexual activity or pornography. The cases were selected from among the children who were subjected to the psychiatric examinations required by the legal authorities. A total of 160 CSA cases were admitted within the data collection period. Of these 105 cases agreed to be involved in the study, and 44 cases were excluded from the study based on the exclusion criteria. The patients were divided into two groups, patients with PTSD and patients without PTSD, based on the results of a structured psychiatric interview. Children who had mental retardation, history of head trauma, and those who received oral contraceptives and psychotropics, previous or current cortisol therapy, and vitamins, and patients who had $\geq 30$ body mass index, chronic systemic disorders, and clinically active infection were excluded in order to prevent interference with biochemical parameters. Furthermore, cases with a psychopathology different from PTSD and depression were excluded from the study. They weren't paid for participation in the study. The patients were evaluated by two experienced psychiatric doctors who had been working with these patient groups for four years. Parents provided informed consent for their children to participate in the study. Inter-rater agreement was 0.70. Ethical approval of the study protocol was obtained from the NonInterventional Clinical Research Ethics Committee at Dicle University Faculty of Medicine.

\section{Study procedures}

Sociodemographic features and clinical dates of the participants were recorded by the psychiatrists. This was followed by a structured psychiatric interview (K-SADS-PL and CAPSCA) and administration of the self-reported Children's Depression Inventory (CDI). Finally, a $2 \mathrm{~mL}$ venous blood sample was obtained for biochemical tests.

\section{Forms and scales}

\section{Sociodemographic data and clinical data form}

This form included questions about age, gender, age of the parents, education level, number of siblings, age at menarche and menstrual cycle, type of abuse, duration and frequency of abuse, relationship with the abuser, and abuse history.

\section{Affective disorders and schizophrenia for school age children-present and lifetime version}

The schedule (K-SADS-PL) was originally developed by Kaufman et al. ${ }^{27}$ It was adapted to the Turkish language by Gökler et al. in 2004. ${ }^{28} \mathrm{~K}$-SADS-PL is administered during an interview with the parents and children, and the final evaluation is performed using input from all data sources. The presence of common psychopathologies in children and adolescents may be investigated with this tool. 


\section{Clinician-administered post-traumatic stress disorder scale for children and adolescents}

CAPS-CA is a semi-structured interview developed to evaluate the frequency and severity of present and past PTSD in children and adolescents according to DSM-III and DSM-IV diagnostic criteria. It was adapted from the Clinician-Administered Post-Traumatic Stress Disorder Scale (CAPS) by Nader et al. in $1996{ }^{29}$ There are totally 36 items in the scale. While seventeen evaluate PTSD symptoms, eight examine other symptoms related to PTSD, such as feelings of guilt, shame, dissociation, change in attachment behavior and trauma related fears. In the current study, other symptoms related to PTSD were not examined, and only PTSD symptoms occurring within the last one month were examined. The total score of the scale ranges between 0 and 68. A diagnosis of PTSD could be made based on the presence of at least one sign of re-experiencing, three symptoms of avoidance or numbing, and two symptoms of a hyper-arousal state. If the patient did not meet these criteria, they were diagnosed as subthreshold PTSD. Each item is scored based both on the children's answers and on a clinical judgment made during the interview. It was adapted to the Turkish language by Karakaya et al..$^{30}$

\section{The children's depression inventory}

The Children's Depression Inventory (CDI) developed by Kovasc based on the Beck Depression scale was used in the study. ${ }^{31}$ However, questions specific to the childhood period such as school success and relationship with the friends were added. The scale was adapted to the Turkish language by Öy ${ }^{32}$ and the scale contains 27 items. Each item is scored as " 0 ", " 1 ", or " 2 " points depending on the severity of the symptom. The highest score is 54 points. High scores indicate the level or severity of depression. The cutoff point for the scale is 19 points.

\section{Biochemical analysis}

The blood samples were obtained in the morning between $1000 \mathrm{~h}$ and $1200 \mathrm{~h}$. The samples were collected into gel tubes. After collection, blood samples were allowed to set for $15 \mathrm{~min}$ utes for clotting. Then, blood samples were centrifuged at $5000 \mathrm{rpm}$ for 6 minutes. The sera were transferred to $1.5 \mathrm{~mL}$ polypropylene tubes and stored at - 80 degrees centigrade until the analysis. Serum levels of cortisol, GPx, coenzyme Q, 8-OHdG, and SOD were determined with an enzyme linked immunosorbent assay (ELISA) method (Hangzhou Eastbiopharm CO. LTD China), according to the manufacturer's instructions. Briefly, samples were added to monoclonal antibody enzyme well which is pre-coated with cortisol monoclonal antibody, incubated; then, cortisol antibodies labeled with biotin were added, and combined with Streptavidin-HRP to form immune complex; then incubation and washing were carried out again to remove the uncombined enzyme. Then Chromogen Solution A, B were added, the color of the liquid changed into the blue, And at the effect of acid, the color was finally become yellow. The absorbance was measured at $450 \mathrm{~nm}$.

\section{Statistical analysis}

The statistical analysis was performed using SPSS 18.0 software package. The student's t-test was used to compare normally distributed variables in independent groups, and the Mann-Whitney test was used to compare not-normally distributed categorical variables. The significance of the difference between the groups in terms of gender, history of psychiatric disorders, or substance abuse in the family members or relatives, type of abuse, frequency and duration of

Table 1. Data related to some sociodemographic variables and scale scores

\begin{tabular}{|c|c|c|c|c|}
\hline & $\operatorname{PTSD}(\mathrm{N}=31)$ & Not PTSD $(\mathrm{N}=30)$ & $\mathrm{z}$ or t value & $\mathrm{p}$ value \\
\hline Age (years) & $14.5 \pm 2.1$ & $13.7 \pm 2.6$ & $\mathrm{z}=-1.35$ & 0.12 \\
\hline $\operatorname{Sex}(M / F)$ & $8 / 23$ & $11 / 19$ & & 0.52 \\
\hline Education duration (years) & $7.3 \pm 1.7$ & $6.7 \pm 2.0$ & $\mathrm{t}=-1.12$ & 0.21 \\
\hline Mother's age (years) & $37.8 \pm 8.1$ & $38.8 \pm 7.5$ & $\mathrm{t}=0.54$ & 0.49 \\
\hline Father's age (years) & $43.4 \pm 8.1$ & $43.1 \pm 7.7$ & $\mathrm{t}=-0.11$ & 0.91 \\
\hline Age at menarche & $12.6 \pm 0.8$ & $12.9 \pm 1.2$ & $z=-0.66$ & 0.47 \\
\hline Date (month) & $24.1 \pm 28.1$ & $21.1 \pm 15.4$ & $\mathrm{t}=-0.85$ & 0.41 \\
\hline CDI & $22.8 \pm 10.2$ & $8.7 \pm 7.1$ & $\mathrm{t}=-5.56$ & 0.01 \\
\hline CAPS-CA-B & $18.1 \pm 4.9$ & $6.5 \pm 5.9$ & $z=-5.63$ & 0.00 \\
\hline CAPS-CA-C & $12.9 \pm 4.5$ & $3.9 \pm 2.9$ & $\mathrm{z}=-5.90$ & 0.00 \\
\hline CAPS-CA-D & $13.2 \pm 5.3$ & $2.7 \pm 3.2$ & $z=-6.13$ & 0.00 \\
\hline
\end{tabular}

PTSD: post-traumatic stress disorder, Date (month): time between the first date of trauma and examination date, CDI: Child Depression Inventory, CAPS-CA: Clinician-Administered Post-Traumatic Stress Disorder Scale for Children and Adolescents 
Table 2. Biochemical parameters in patients with or without post-traumatic stress disorder

\begin{tabular}{|c|c|c|c|c|}
\hline & PTSD $(\mathrm{N}=31)$ & Not PTSD $(\mathrm{N}=30)$ & $z$ value & $\mathrm{p}$ \\
\hline \multicolumn{5}{|l|}{ HPA axis } \\
\hline Cortisol (ng/mL) & $91.3 \pm 65.8$ & $92.8 \pm 74.4$ & -0.12 & 0.91 \\
\hline \multicolumn{5}{|l|}{ Oxidative stress } \\
\hline $\mathrm{GPx}(\mathrm{U} / \mathrm{mL})$ & $90.7 \pm 55.6$ & $83.2 \pm 50.2$ & -0.52 & 0.61 \\
\hline $\mathrm{SOD}(\mathrm{U} / \mathrm{L})$ & $151.3 \pm 149.8$ & $147.6 \pm 155.9$ & -0.31 & 0.76 \\
\hline Coenzyme Q (ng/mL) & $114.8 \pm 144.3$ & $127.6 \pm 160.2$ & -0.02 & 0.99 \\
\hline \multicolumn{5}{|l|}{ DNA damage } \\
\hline 8-OHdG (ng/mL) & $22.9 \pm 24.0$ & $23.2 \pm 28.9$ & -0.40 & 0.69 \\
\hline
\end{tabular}

abuse, relationship with the abuser was evaluated using the chi-square test or Fisher's exact test, where appropriate. Pearson's test was used to evaluate correlation coefficients and statistically significance of normally distributed variables, and Spearman's test was used to evaluate not normally distributed variables. A p value below 0.05 was considered statistically significant.

\section{RESULTS}

The mean age was $13.3 \pm 2.4$ years (range: $5-17$ years) among the victims of sexual abuse. Our evaluation revealed a diagnosis of PTSD in 51\% $(n=31)$ of victims. There was no significant difference between patients with or without PTSD in terms of gender, smoking status, and menstrual cycle, the latter being assessed for adolescent patients. There was also no significant difference between the groups in terms of age, age of the mother/father. Data related to some sociodemographic variables and scale scores are presented in Table 1.

Regarding the parameters related to sexual abuse, $48 \%$ $(n=29)$ of the victims experienced sexual abuse involving penetration. Of the victims, $46 \%(\mathrm{n}=28)$ experienced single assault and $54 \%(n=33)$ experienced multiple assaults. $21 \%$ $(n=13)$ of victims experienced sexual abuse within the family (incestuous), and 79\% ( $n=48)$ experienced sexual abuse committed by non-related persons. There was no significant difference between patients with or without PTSD in terms of relationship with the abuse and presence of penetration ( $\mathrm{p}=0.34$ and $\mathrm{p}=0.68$, respectively). However, the rate of PTSD was higher in patients who experienced multiple sexual assaults compared to the victims of a single assault $(\mathrm{p}=0.01)$. The rate of depression was significantly higher in patients with PTSD ( $\mathrm{p}=0.01)$.

There was no significant difference between the groups with or without PTSD in terms of cortisol, GPx, SOD, coenzyme Q, and 8-OHdG levels (Table 2). Likewise, there was no significant difference between the groups with or without

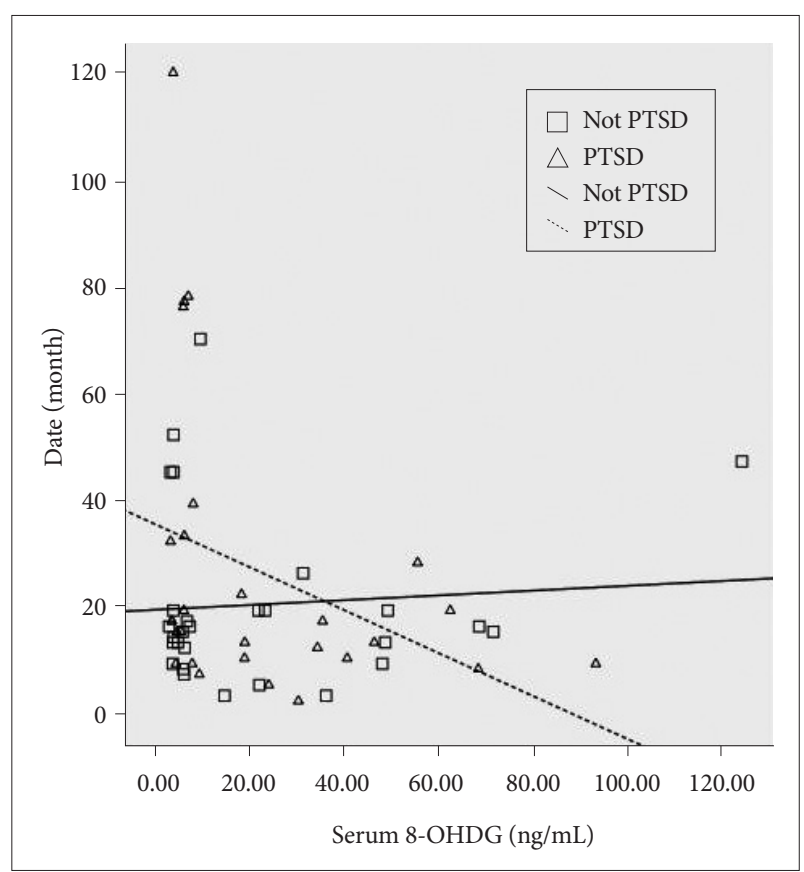

Figure 1. Time $\times$ 8-OHdG interaction. 8-OHdG levels in the PostTraumatic Stress Disorder (PTSD) group decreased with increasing time after trauma, and there was no significant correlation with 8-OHdG levels in patients without PTSD $(r=-0.42, p=0.03$ and $r=-0.04, p=0.85$, respectively). The mean time that elapsed since the first sexual abuse until the date of examination was $23.9 \pm 24.1$ months (range: $1-115$ months).

depression in terms of cortisol, GPx, SOD, coenzyme Q, and 8-OHdG levels ( $\mathrm{p}=0.43, \mathrm{p}=0.46, \mathrm{p}=0.38, \mathrm{p}=0.53$, and $\mathrm{p}=0.48$, respectively). There was no correlation between CAPS scores and GPx, SOD, coenzyme Q, and 8-OHdG levels between patients with or without PTSD.

The mean time that elapsed since the first sexual abuse until the date of examination was $23.9 \pm 24.1$ months (range: 1-115 months). There is no difference between PTSD and non-PTSD group according to their mean time that elapsed since the first sexual abuse until the date of examination $(p=0.41)$. In the PTSD group, cortisol levels decreased with increasing time after trauma, and there was no significant 
correlation with the cortisol levels in patients without PTSD $(\mathrm{r}=-0.46, \mathrm{p}=0.01$ and $\mathrm{r}=-0.07, \mathrm{p}=0.73$, respectively). Similarly, 8-OHdG levels in the PTSD group decreased with increasing time after trauma, and there was no significant correlation with 8-OHdG levels in patients without PTSD $(\mathrm{r}=-0.42$, $\mathrm{p}=$ 0.03 and $\mathrm{r}=-0.04, \mathrm{p}=0.85$, respectively) (Figure 1 ).

\section{DISCUSSION}

In the present study, there was no significant difference between patients with or without PTSD in terms of oxidative stress and DNA damage. Furthermore, no relationship was found between the severity of the symptoms of PTSD and oxidative stress and DNA damage. In their study, Tezcan et al. ${ }^{24}$ and Čeprnja et al. ${ }^{23}$ did not report any association between PTSD and oxidative stress. However, healthy volunteers having no past history of trauma were selected as the control group in their study. In addition, the type of trauma in their study was different compared to the present study. In contrast to our findings, human and animal studies showed an association between oxidative stress and anxiety. ${ }^{16-21}$ In an animal model of PTSD, inflammation and oxidative stress were reported to play a critical role in the development and exacerbation of PTSD. ${ }^{22}$

In the present study, cortisol and 8-OHdG levels decreased with increasing time after trauma in the PTSD group. Although we did not find any difference between the groups in terms of 8-OHdG concentrations, this finding was considered to be a reflection of the relationship between cortisol and DNA damage. In addition, the decrease in cortisol levels in time was suggested to be a reflection of adaptive process preventing harmful effects of prolonged exposure to high cortisol levels on brain structures such as the hippocampus and frontal cortex. ${ }^{33}$

The present study had several limitations. Biochemical parameters were analyzed in serum samples. The sources other than brain may have effects on the consequences. The present study performed single measurements to determine cortisol levels. This study did not include a healthy control group that did not have a history of trauma.

In conclusion, there was no significant difference between children and adolescents with or without PTSD after sexual abuse in terms of the level of oxidative stress and DNA damage. However, cortisol and 8-OHdG levels decreased with increasing time after trauma in the PTSD group. Although we did not find any difference between the groups in terms of 8-OHdG concentrations, this finding was considered to be a reflection of the relationship between cortisol and DNA damage. This is the first study conducted in this age group. On the other hand, longitudinal studies with larger sample size are required to confirm the findings of the current study.

\section{Acknowledgments}

We would like to thank Dr. Rümeysa Alaca, and our patients and their parents for taking part in this study.

\section{REFERENCES}

1. American Psychiatric Association. Diagnostic and Statistical Manual of Mental Disorders, Fourth Edition, Text Revision (DSM-IV-TR). Washington, DC: American Psychiatric Association; 2000.

2. Simmons JG, Whittle SL, Patton GC, Dudgeon P, Olsson C, Byrne ML, et al. Study protocol: imaging brain development in the Childhood to Adolescence Transition Study (iCATS). BMC Pediatr 2014;14:115.

3. Feiring C, Taska L, Lewis M. Age and gender differences in children's and adolescents' adaptation to sexual abuse. Child Abuse Negl 1999; 23:115-128.

4. Maniglio R. The impact of child sexual abuse on health: a systematic review of reviews. Clin Psychol Rev 2009;29:647-657.

5. Yehuda R. Status of Glucocorticoid Alterations in Post-traumatic Stress Disorder. In: Judd LL, Sternberg EM, Editors. Glucocorticoids and Mood Clinical Manifestations, Risk Factors, and Molecular Mechanisms.Vol 1179. Malden: Wiley-Blackwell; 2009. p.56-69.

6. Serafini M, Del Rio D. Understanding the association between dietary antioxidants, redox status and disease: is the Total Antioxidant Capacity the right tool? Redox Rep 2004;9:145-152.

7. Bouayed J, Rammal H, Soulimani R. Oxidative stress and anxiety: relationship and cellular pathways. Oxid Med Cell Longev 2009;2:63-67.

8. Halliwell B. Oxidative stress and neurodegeneration: where are we now? J Neurochem 2006;97:1634-1658.

9. Ng F, Berk M, Dean O, Bush AI. Oxidative stress in psychiatric disorders: evidence base and therapeutic implications. Int J Neuropsychopharmacol 2008;11:851-876.

10. Hovatta I, Juhila J, Donner J. Oxidative stress in anxiety and comorbid disorders. Neurosci Res 2010;68:261-275.

11. Valko M, Leibfritz D, Moncol J, Cronin MTD, Mazur M, Telser J. Free radicals and antioxidants in normal physiological functions and human disease. Int J Biochem Cell Biol 2007;39:44-84.

12. Massaad CA, Klann E. Reactive oxygen species in the regulation of synaptic plasticity and memory. Antioxid Redox Signal 2011;14:20132054 .

13. Ernster L, Dallner G. Biochemical, physiological and medical aspects of ubiquinone function. Biochim Biophys Acta 1995;1271:195-204.

14. Beal MF. Coenzyme Q10 as a possible treatment for neurodegenerative diseases. Free Radic Res 2002;36:455-460.

15. Berk M. Neuroprogression: pathways to progressive brain changes in bipolar disorder. Int J Neuropsychopharmacol 2009;12:441-445.

16. Gingrich JA. Oxidative stress is the new stress. Nat Med 2005;11:12811282.

17. Hovatta I, Tennant RS, Helton R, Marr RA, Singer O, Redwine JM, et al. Glyoxalase 1 and glutathione reductase 1 regulate anxiety in mice. Nature 2005;438:662-666.

18. Berry A, Capone F, Giorgio M, Pelicci PG, de Kloet ER, Alleva E, et al. Deletion of the life span determinant p66Shc prevents age-dependent increases in emotionality and pain sensitivity in mice. Exp Gerontol 2007;42:37-45.

19. Arranz L, Guayerbas N, De la Fuente M. Impairment of several immune functions in anxious women. J Psychosom Res 2007;62:1-8.

20. Bouayed J, Rammal H, Younos C, Soulimani R. Positive correlation between peripheral blood granulocyte oxidative status and level of anxiety in mice. Eur J Pharmacol 2007;564:146-149.

21. Masood A, Nadeem A, Mustafa SJ, O’Donnell JM. Reversal of oxidative stress-induced anxiety by inhibition of phosphodiesterase- 2 in mice. J Pharmacol Exp Ther 2008;326:369-379. 
22. Wilson CB, McLaughlin LD, Nair A, Ebenezer PJ, Dange R, Francis J. Inflammation and oxidative stress are elevated in the brain, blood, and adrenal glands during the progression of post-traumatic stress disorder in a predator exposure animal model. PLoS One 2013;8:e76146.

23. Čeprnja M, Derek L, Unić A, Blazev M, Fistonić M, Kozarić-Kovacić $\mathrm{D}$, et al. Oxidative stress markers in patients with post-traumatic stress disorder. Coll Antropol 2011;35:1155-1160.

24. Tezcan E, Atmaca M, Kuloglu M, Ustundag B. Free radicals in patients with post-traumatic stress disorder. Eur Arch Psychiatry Clin Neurosci 2003;253:89-91.

25. Colaianna M, Schiavone S, Zotti M, Tucci P, Morgese MG, Bäckdahl L, et al. Neuroendocrine profile in a rat model of psychosocial stress: relation to oxidative stress. Antioxid Redox Signal 2013;18:1385-1399.

26. Richards RS, Nwose EU, Bwititi P. Biochemical basis of circadian rhythms and diseases: with emphasis on post-traumatic stress disorder. Med Hypotheses 2011;77:605-609.

27. Kaufman J, Birmaher B, Brent D, Rao U, Flynn C, Moreci P, et al. Schedule for Affective Disorders and Schizophrenia for School-Age ChildrenPresent and Lifetime Version (K-SADS-PL): initial reliability and validity data. J Am Acad Child Adolesc Psychiatry 1997;36:980-988.
28. Gökler B, Ünal F, Pehlivantürk B, Kültür EÇ, Akdemir D, Taner Y. Reliability and validity of schedule for affective disorders and schizophrenia for school age children-present and lifetime version-turkish version (K-SADS-PL-T). Turk J Child Adolesc Ment Health 2004;11:109116.

29. Nader K, Kriegler J, Blake D. Clinician Administered PTSD Scale for Children and Adolescents. Boston, MA: National center for PTSD, Boston Veterans Administration Medical Center; 1996.

30. Karakaya I, Memik NC, Ağaoğlu B, Aker AT, Şişmanlar ŞG, Öç ÖY et al. Reliability and validity Of Clinician Administered Post Traumatic Stres Disorder Scale for Children and Adolescents (CAPS-CA). Turk J Child Adolesc Ment Health 2007;14:125-132.

31. Kovacs M. The Children's Depression Inventory (CDI). Psychopharmocol Bull 1985;21:995-998.

32. Öy B. The children's depression inventory: validity and reliability study. Turk J Psychiatry 1991;1:132-136.

33. De Bellis MD, Kuchibhatla M. Cerebellar volumes in pediatric maltreatment-related posttraumatic stress disorder. Biol Psychiatry 2006; 60:697-703. 